\title{
Editorial: Dysfunction and Repair of Neural Circuits for Motor Control
}

\author{
Andrew Paul Tosolini ${ }^{1 *}$, George Z. Mentis ${ }^{2 * \dagger}$ and John H. Martin ${ }^{3 * t}$ \\ ${ }^{1}$ Department of Neuromuscular Diseases, UCL Queen Square Institute of Neurology, University College London, London, \\ United Kingdom, ${ }^{2}$ Department of Pathology \& Cell Biology and Neurology, Center for Motor Neuron Biology and Disease, \\ Columbia University, New York, NY, United States, ${ }^{3}$ Department of Molecular, Cellular and Biomedical Sciences, Center for \\ Discovery and Innovation, City University of New York School of Medicine, New York, NY, United States
}

Keywords: motor neurons, sensory neurons, regeneration, spinal cord injury, ALS, SMA, inflammation, glia

\section{Editorial on the Research Topic}

\section{Dysfunction and Repair of Neural Circuits for Motor Control}

The dissolution of normal behavior in pathological conditions, after trauma, or in neurodegenerative diseases is often attributed to the selective dysfunction and degeneration of particular classes of vulnerable neurons. However, vulnerable neurons are embedded in neuronal circuits that often play major roles in the progression of the pathophysiological state, by cell-autonomous and non-cell autonomous mechanisms. For example, voluntary motor behavioral impairments occur after brain or spinal cord injury because descending projection neurons are vulnerable to axonal damage and are unable to regenerate anew. This limitation reflects both a loss of intrinsic axon regenerative capacity in mature neurons and extrinsic regulation by non-neuronal cells. Similarly, motor neurons deprived of supraspinal inputs or in neurodegeneration (e.g., ALS, SMA) undergo an array of well-described molecular events (Schwab and Bartholdi, 1996; Brown and Al-Chalabi, 2017; Groen et al., 2018) that also include morphological remodeling (Bose et al., 2005; Dukkipati et al., 2018). If therefore, repair or restoration of normal function is sought after, a clear understanding is required for the molecular, cellular, and neuronal circuit mechanisms involved. Over the last decade, several significant advances in our understanding of the development and operational principles of neural circuits demonstrate the complexity of the central nervous system under normal conditions and the diverse mechanisms that lead to dysfunction.

Everyday actions in essential complex behaviors such as walking, feeding, and breathing, require the specific integration of neural circuits that flawlessly operate with precision, co-ordination, and synchrony (Arber, 2012). As summarized in Figure 1, for voluntary movement to occur, the motor cortical areas must initiate communication with the spinal cord circuitry, which in turn convey these commands via spinal motor neurons to the skeletal muscles. Equally important, sensory information from the periphery is essential for the proper activation and function of neural circuits involved in motor control. Intrinsic to these processes are the influences of spinal excitatory and inhibitory interneurons.

However, after injury or in disease states, these neural circuits may be affected in subtle ways but over time may result in a multitude of effects causing dysfunction; not only in vulnerable neurons but also by disrupting the signaling and connectivity of integrated neural circuits. As neural circuits are disrupted through trauma [spinal cord injury (SCI), peripheral nerve injury, stroke] or in neurodegenerative diseases [amyotrophic lateral sclerosis (ALS), spinal muscular atrophy (SMA)], determining the timing and primacy of the earliest pathological events are critical questions to be addressed if normal function is to be restored. Uncovering therefore the initiating pathogenic events are critical steps in proposing potential therapeutic avenues. 


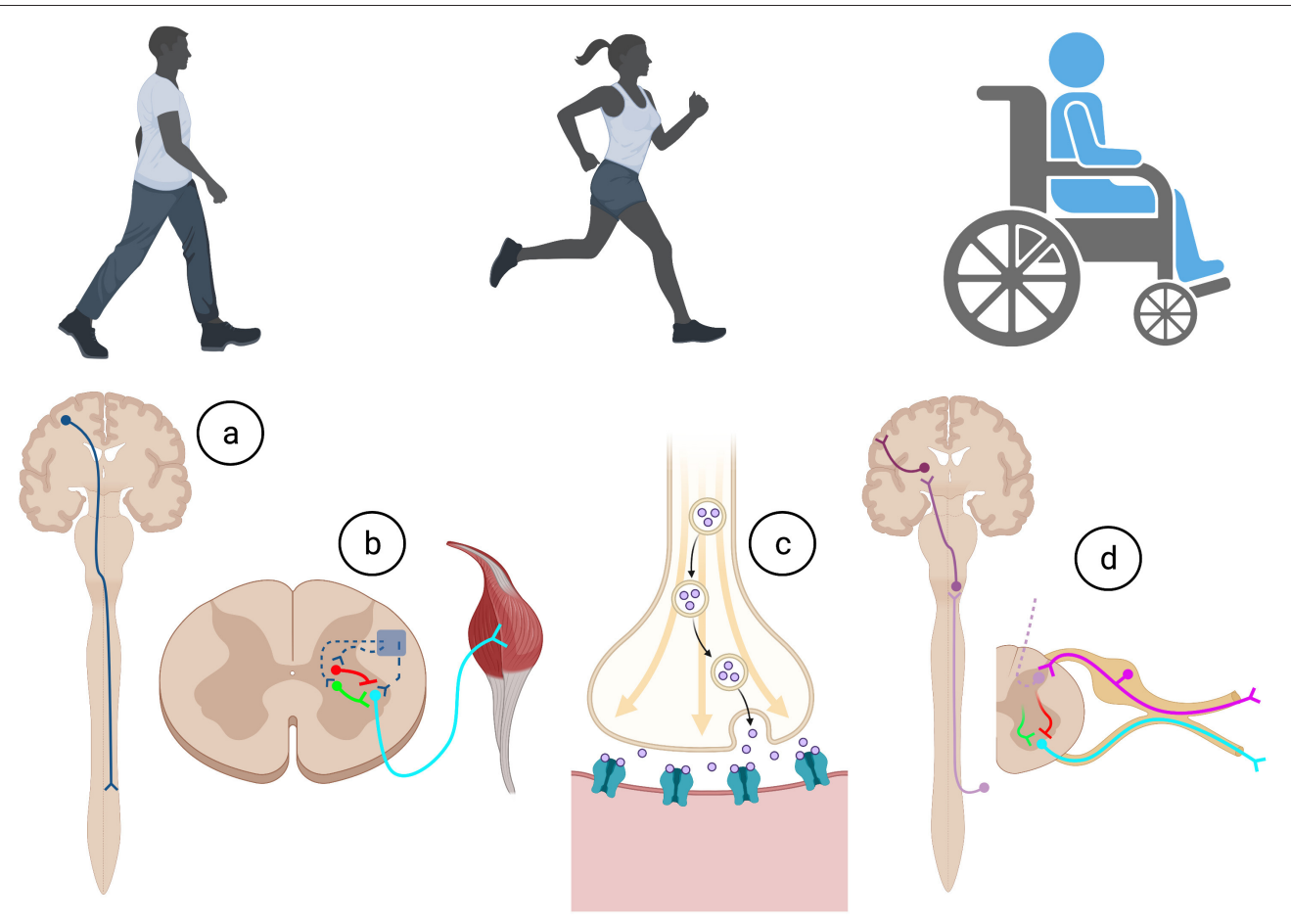

FIGURE 1 | Execution of all movements in health and after trauma require a complex series of co-ordination of cellular and molecular actions involved within the (A) descending motor system, (B) intrinsic spinal cord circuitry, (C) neuromuscular junction, and (D) afferent feedback through the ascending sensory system. Created with BioRender.com.

However, a paramount challenge for the field is to harmonize and integrate effectively the increasing number of studies that separately focus on molecular events in single cells (e.g., transcriptomics, proteomics) or on cellular phenotypes in neurons and glia (e.g., neuronal dysfunction, neurodegeneration, synaptic plasticity, astrocytic, or microglia proliferation) (Stuart and Satija, 2019). To this end, an exciting challenge is to decipher adaptive from maladaptive molecular and cellular changes within individual neurons and their supporting cells and the influence they exert on motor circuits after neural trauma (Ilieva et al., 2009; Eroglu and Barres, 2010; Huntley, 2012). We launched this Research Topic to provide a platform to encourage discussion on recent advances in knowledge and/or therapeutic tools to investigate motor circuitry following certain pathological conditions.

The topic on Dysfunction and Repair of Neural Circuits for Motor Control is devoted to neuronal circuits involving cortical, spinal, and peripheral neurons in healthy and pathological conditions. The articles in this collection-comprising five original studies, three extensive-reviews and two mini-reviewsexplore how certain circuits regulate and integrate their actions, how they are altered in disease or after trauma, and efforts to repair circuits to restore normal function. Discussions span human and animal models of impaired motor circuits and a focus that includes much of the neuraxis: the motor cortex, hindbrain, spinal cord, somatic sensory neurons, and peripheral nerves.
The five original studies traverse the neuroanatomical spectrum, spanning hindbrain neurons, upper motor neurons, and sensory neurons to glial-peripheral nerve interactions, with particular focus on regeneration, inflammation, and excitability in ALS animal models (Table 1). Huang et al. study the modulation of miR-133b to promote axon regeneration of Mauthner-cells in zebrafish hindbrain. Ballou et al. characterize the inflammatory and glial response to cortical transplants after injury. Chen et al. reveal the involvement of Schwann cells in peripheral nerve regeneration. Zeng et al. describe inflammation cascades in DRG sensory neurons. Jara et al. describe circuitry changes in the motor cortex of pre-symptomatic ALS mice.

The five reviews discuss signaling cascades involving motor neurons, sensory neurons, spinal motor circuits, and electrical stimulation relevant for ALS, SMA, SCI, and regeneration (Table 2). Sobrido-Cameán and Barreiro-Iglesias consider apoptotic signaling cascades after SCI. Shorrock et al. discuss sensory-motor molecular mechanisms in SMA. Eisdorfer et al. contemplate how epidural electrical stimulation can enhance motility after SCI. Alvarez et al. examine the influence of spinal cord circuitry in regeneration of peripheral nerves. Falgairolle and O'Donovan deliberate on the influence of motor circuits on motor neuron vulnerability in ALS and SMA. 
TABLE 1 | Highlights from the original research published within this Research Topic.

\begin{tabular}{|c|c|c|c|}
\hline Paper & Purpose & Highlights & $\begin{array}{l}\text { Model and neuron } \\
\text { location }\end{array}$ \\
\hline Huang et al. & $\begin{array}{l}\text { To examine the role of } \\
\text { miR-133b in Mauthner-cell } \\
\text { regeneration in zebrafish }\end{array}$ & $\begin{array}{l}\text { - Overexpression of miR-133b inhibited axon } \\
\text { regeneration, whereas down-regulation of } \\
\text { miR-133b, promoted axon outgrowth } \\
\text { - miR-133b regulates axon regeneration by directly } \\
\text { targeting tppp3, a novel regeneration-associated } \\
\text { gene which belongs to Tubulin } \\
\text { polymerization-promoting protein family } \\
\text { - miR-133b overexpression attenuated } \\
\text { mitochondrial motility in M-cells in vivo, correlating } \\
\text { with enhanced axon regenerative properties }\end{array}$ & $\begin{array}{l}\text { Wild-type, Zebrafish, } \\
\text { Hindbrain }\end{array}$ \\
\hline Ballout et al. & $\begin{array}{l}\text { - To determine the extent } \\
\text { to which post-traumatic } \\
\text { inflammation following } \\
\text { cortical lesion could } \\
\text { influence the survival of } \\
\text { grafted neurons, } \\
\text { - To understand the } \\
\text { development of their } \\
\text { projections to target brain } \\
\text { regions whilst } \\
\text { understanding how } \\
\text { transplanted cells can } \\
\text { modulate } \\
\text { host inflammation }\end{array}$ & $\begin{array}{l}\text { - Embryonic motor cortical tissue grafted } 1 \text { week } \\
\text { after adult motor cortex lesion resulted in an } \\
\text { increasing numbers of astrocytes, microglia, } \\
\text { oligodendrocytes and hematopoietic cells, } \\
\text { compared to implanted grafts at the time of lesion } \\
\text { - One week after cortical lesion resulted in more } \\
\text { recruitment and activation of inflammatory brain } \\
\text { resident mediators and peripheral infiltrating cells } \\
\text { compared to day 0 } \\
\text { - Graft implantation one week after cortical lesion } \\
\text { resulted in (i) increased recruitment of A2 } \\
\text { astrocytes in the host transplant and adjacent } \\
\text { cortex, (ii) increased oligodendrocytes only within } \\
\text { the transplant, and (iii) decreased M1 microglia } \\
\text { only within the transplant }\end{array}$ & $\begin{array}{l}\text { Wild-type Mouse, } \\
\text { Motor cortex }\end{array}$ \\
\hline Chen et al. & $\begin{array}{l}\text { - To understand the } \\
\text { behavior of Schwann cells } \\
\text { migrating into a nerve gap } \\
\text { following a transection } \\
\text { injury } \\
\text { - To reveal their interactions } \\
\text { with regenerating axons } \\
\text { within the nerve bridge }\end{array}$ & $\begin{array}{l}\text { - After peripheral transection, axonal outgrowth first } \\
\text { begins from the proximal stump, followed by } \\
\text { Schwann cells migration from proximal and distal } \\
\text { nerve stumps } \\
\text { - Schwann cells overtake the axonal outgrowth, } \\
\text { forming Schwann cell cords within the nerve } \\
\text { bridge and most regenerating axons attach to the } \\
\text { migrating Schwann cells and follow their } \\
\text { trajectory across the nerve gap } \\
\text { - Schwann cells play a crucial role in controlling the } \\
\text { directionality and speed of axon regeneration } \\
\text { across the nerve gap }\end{array}$ & $\begin{array}{l}\text { Wild-type Mouse, } \\
\text { Peripheral Nerve }\end{array}$ \\
\hline Jara et al. & $\begin{array}{l}\text { Determine the mechanisms } \\
\text { that contribute to upper } \\
\text { motor neuron vulnerability in } \\
\text { hSOD1 }{ }^{G 93 A} \text { mice }\end{array}$ & $\begin{array}{l}\text { - Pre-symptomatic hSOD1G93A mice display altered } \\
\text { inhibitory, but not excitatory, circuitry specific to } \\
\text { the } L 2 / 3 \text { pyramidal neurons in the motor cortex } \\
\text { - Exon microarray analysis provides some } \\
\text { molecular evidence of altered inhibitory } \\
\text { transmission in hSOD1 }{ }^{G 93 A} \text { upper motor neurons } \\
\text { - GABA and potassium receptor subunits are } \\
\text { differentially expressed in diseased corticospinal } \\
\text { motor neurons in hSOD1 }{ }^{G 93 A} \text { mice }\end{array}$ & $\begin{array}{l}\text { hSOD1 }{ }^{\text {G93A }} \text { Mouse, } \\
\text { Motor cortex }\end{array}$ \\
\hline
\end{tabular}


TABLE 2 | Highlights from the mini- and full- reviews published within this Research Topic.

\begin{tabular}{|c|c|c|c|}
\hline Paper & Highlights & Paper type & $\begin{array}{l}\text { Disease/Dysfunction } \\
\text { model }\end{array}$ \\
\hline $\begin{array}{l}\text { Sobrido-Cameán } \\
\text { and } \\
\text { Barreiro-Iglesias }\end{array}$ & $\begin{array}{l}\text { - Reviews the literature on caspase-8 mediated cell death after spinal cord } \\
\text { injury in a variety of animal models } \\
\text { - Discusses caspase-8 activated signaling pathways following spinal cord } \\
\text { injury } \\
\text { - Proposes novel areas to advance the knowledge on the role of caspase-8 } \\
\text { and Fas in cell death after spinal cord injury }\end{array}$ & Mini-Review & Spinal Cord Injury (SCl) \\
\hline Eisdorfer et al. & $\begin{array}{l}\text { - Describes the utility of epidural electrical stimulation (EES) in enhancing } \\
\text { motility in SCI patients } \\
\text { - Identifies several sensorimotor plasticity mechanisms that are considered } \\
\text { to be evoked by EES through the activation of peripheral afferents } \\
\text { - Evaluates emerging genetic modification tools that modulate afferent } \\
\text { fibers to uncovering molecular and circuit mechanisms of EES-induced } \\
\text { recovery from SCl }\end{array}$ & Review & Spinal Cord Injury (SCl) \\
\hline Alvarez et al. & $\begin{array}{l}\text { - Provides a comprehensive conceptual framework to understand how } \\
\text { different types of nerve injuries that result in motor neuron axotomy } \\
\text { induce distinct regenerative programs that drastically differ in motoneuron } \\
\text { preservation, and speed and efficiency of regeneration } \\
\text { - Proposes that synaptic plasticity of axotomized motor neurons should be } \\
\text { divided into two distinct processes: (1) a reversible, rapid, } \\
\text { cell-autonomous, microglia-independent shedding of synapses; and (2) a } \\
\text { slower, microglial dependent mechanism that permanently alters spinal } \\
\text { cord circuitry } \\
\text { - Considers the significance of differential removal of excitatory and } \\
\text { inhibitory synapses on synaptic plasticity of axotomized motor neurons }\end{array}$ & Review & Peripheral Nerve Injury \\
\hline
\end{tabular}

Overall, this Research Topic describes anatomical, electrophysiological, cellular, and molecular interactions between neural networks and how advancing technologies enable clearer characterizations of dysfunctional neural circuitry.

\section{AUTHOR CONTRIBUTIONS}

All authors listed have made a substantial, direct and intellectual contribution to the work, and approved it for publication.

\section{REFERENCES}

Arber, S. (2012). Motor circuits in action: specification, connectivity, and function. Neuron. 74, 975-989. doi: 10.1016/j.neuron.2012. 05.011

\section{FUNDING}

AT holds a postdoctoral position supported by a Wellcome Trust Senior Investigator Award [107116/Z/15/Z] to Giampietro Schiavo (Institute of Neurology, University College London). GZM has been supported by the NINDS, NIH (R01-NS078375), The NIH Blueprint for Neuroscience Research, NIAAA and NINDS (R01-AA027079), the Department of Defense (GR.10235006), The SMA Foundation and Project-ALS. JHM was supported by NIH (R01NS064004), NYS Dept of Health Spinal Cord Injury Research Board (C31291GG), Paralyzed Veterans Association (3160), and The Craig H Neilsen Foundation (547040).

Bose, P., Parmer, R., Reier, P. J., and Thompson, F. J. (2005). Morphological changes of the soleus motoneuron pool in chronic midthoracic contused rats. Exp. Neurol. 191, 13-23. doi: 10.1016/j.expneurol.2004.08.028

Brown, R. H., and Al-Chalabi, A. (2017). Amyotrophic lateral sclerosis. N. Engl. J. Med. 377, 162-172. doi: 10.1056/NEJMra1603471 
Dukkipati, S. S., Garrett, T. L., and Elbasiouny, S. M. (2018). The vulnerability of spinal motoneurons and soma size plasticity in a mouse model of amyotrophic lateral sclerosis. J. Physiol. 596, 1723-1745. doi: 10.1113/JP275498

Eroglu, C., and Barres, B. A. (2010). Regulation of synaptic connectivity by glia. Nature 468, 223-231. doi: 10.1038/nature09612

Groen, E. J. N., Talbot, K., and Gillingwater, T. H. (2018). Advances in therapy for spinal muscular atrophy: promises and challenges. Nat. Rev. Neurol. 14, 214-224. doi: 10.1038/nrneurol.2018.4

Huntley, G. W. (2012). Synaptic circuit remodelling by matrix metalloproteinases in health and disease. Nat. Rev. Neurosci. 13, 743-757. doi: 10.1038/nrn3320

Ilieva, H., Polymenidou, M., and Cleveland, D. W. (2009). Non-cell autonomous toxicity in neurodegenerative disorders: ALS and beyond. J. Cell Biol. 187, 761-772. doi: $10.1083 /$ jcb.200908164

Schwab, M. E., and Bartholdi, D. (1996). Degeneration and regeneration of axons in the lesioned spinal cord. Physiol. Rev. 76, 319-370. doi: 10.1152/physrev.1996.76.2.319
Stuart, T., and Satija, R. (2019). Integrative single-cell analysis. Nat. Rev. Genetics 20, 257-272. doi: 10.1038/s41576-01 9-0093-7

Conflict of Interest: The authors declare that the research was conducted in the absence of any commercial or financial relationships that could be construed as a potential conflict of interest.

Copyright (c) 2021 Tosolini, Mentis and Martin. This is an open-access article distributed under the terms of the Creative Commons Attribution License (CC BY). The use, distribution or reproduction in other forums is permitted, provided the original author(s) and the copyright owner(s) are credited and that the original publication in this journal is cited, in accordance with accepted academic practice. No use, distribution or reproduction is permitted which does not comply with these terms. 